Alma Mater Studiorum - Università di Bologna DEPARTMENT OF ECONOMICS

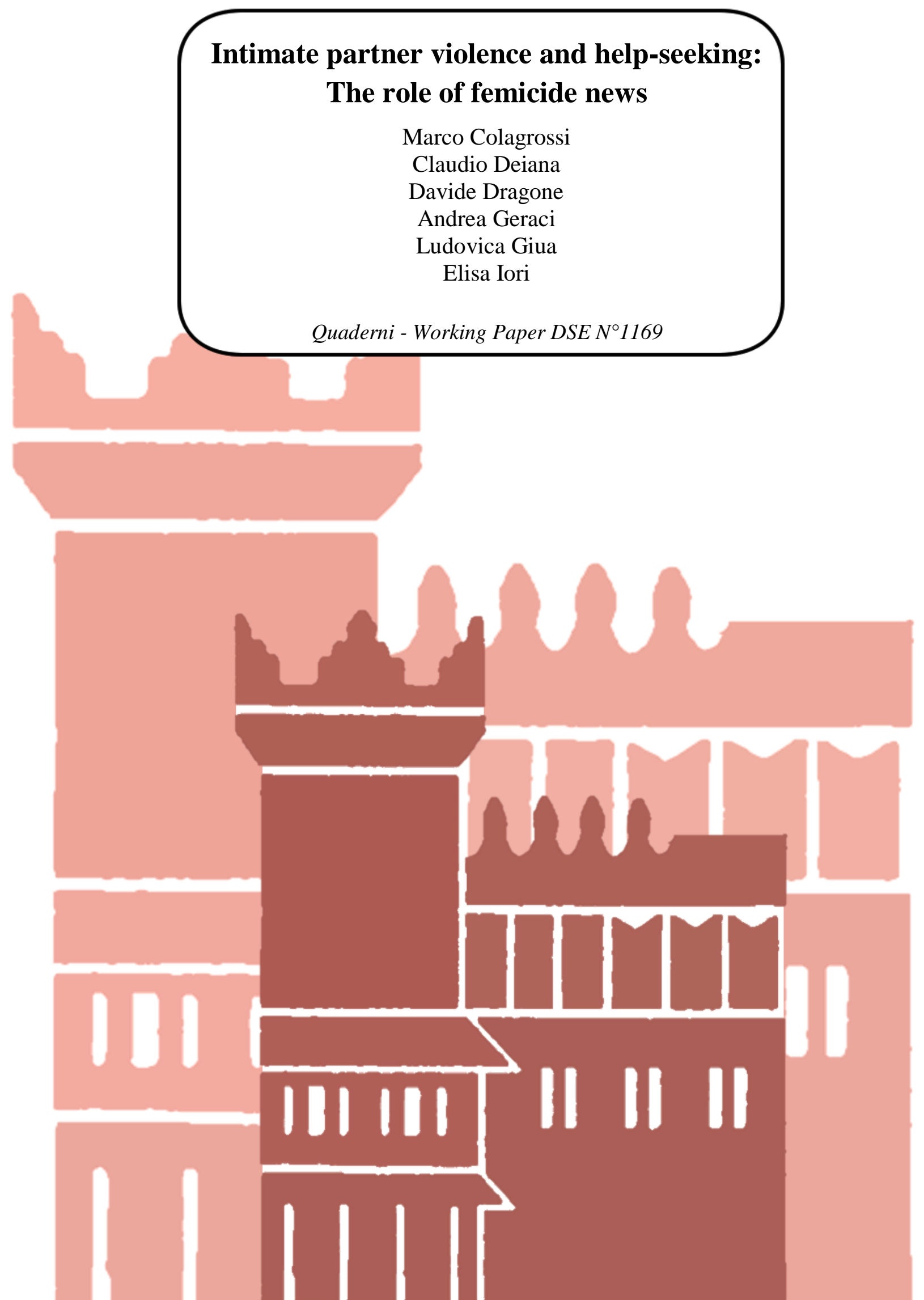




\title{
Intimate partner violence and help-seeking: The role of femicide news
}

\author{
Marco Colagrossi ${ }^{1}$, Claudio Deiana*2, Davide Dragone ${ }^{3}$, Andrea Geraci ${ }^{1}$, Ludovica Giua $^{1}$, and \\ Elisa Iori $^{3}$ \\ ${ }^{1}$ European Commission, Joint Research Centre \\ ${ }^{2}$ University of Cagliari, CRENoS and University of Essex \\ ${ }^{3}$ University of Bologna
}

January, 2022

\begin{abstract}
Exploiting high-frequency data from the Italian anti-violence helpline and a unique geolocalized dataset on killings of women, we show that the news coverage of a femicide triggers an increase in calls to the helpline. The effect is detectable in the week following the news and in the province where the femicide has occurred. These findings are consistent with a model in which the news of a femicide increase expectations about future intimate partner violence in case no call is made.
\end{abstract}

Keywords: Gender-based violence; Helpline; Intimate partner violence; Physical violence; Psychological violence, Sexual violence.

JEL codes: I18; I38; J12.

${ }^{*}$ Corresponding author: claudio.deiana@unica.it.

We are grateful to the Italian Department of Equal Opportunities, to the Italian National Institute of Statistics and to Casa delle Donne per Non Subire Violenza ONLUS for generously sharing their data. Opinions expressed herein are those of the authors only and do not reflect the views of, or involve any responsibility for, the institutions to which they are affiliated. Any errors are the fault of the authors only. 


\section{Non-Technical Summary}

\section{"Intimate partner violence and help-seeking: The role of femicide news"}

by Marco Colagrossi (European Commission, Joint Research Centre), Claudio Deiana (Università di

Cagliari, CRENoS and University of Essex), Davide Dragone (Università di Bologna), Andrea Geraci

(European Commission, Joint Research Centre), Ludovica Giua (European Commission, Joint Research

Centre), Elisa Iori (Università di Bologna)

Violence against women is a violation of human rights. Not only it produces consequences on the survivors' physical and mental health, but it also hampers female autonomy and self-realization. Femicides are the extreme realisation of a much more common phenomenon of violence perpetrated against women. In the EU, $33 \%$ of women have been physically or sexually abused since the age of 15 .

In this paper, we investigate help-seeking behaviour of survivors of intimate partner violence. We study how victims of intimate partner violence react to the news of a femicide by estimating whether it triggers calling a helpline and reaching out for help and support. In principle, the response is not obvious: one one hand news about a femicide might foster help-seeking by increasing the victims' expectations about future violence if no action is taken, or by raising the expected benefit associated with help-seeking. On the other hand, the femicide news might reduce the helpline calls if they increase the fear of retaliation by the violent offender.

Which of the two effects dominates is an empirical question that we address using two unique Italian databases. The first one, compiled by the Department for Equal Opportunities of the Italian Government, collects the weekly number of calls to the national hotline service 1522, which refers survivors of violence to shelters and antiviolence centres. The service is available 24 hours a day / 7 days a week and can be accessed anonymously. The second one is a geolocalized high-frequency dataset on killings of girls and women compiled by the Italian non-governmental organization Casa delle Donne per Non Subire Violenza, which is specialized in providing support and shelter for women who undergo violence. The data cover the period January 1-May 31 for the years 2015-2019.

We find that after a femicide is reported in the news, calls to the helpline increase by about $21 \%$. The effect appears to be short-lived, and geographically localised. These findings are consistent with the femicide news increasing the survivor's expectations about future intimate partner violence. Specifically, the empirical evidence suggests that the 
news make increased expectation of future violence in case of inaction more salient than the fear of retaliation in case no action is taken.

These results highlight that talking about femicides not only raises awareness about the existence of violence against women, but it is also an important trigger for help-seeking behavior by the survivors of intimate partner violence. This is commonly recognized as an important step to end intimate partner violence, and our paper provides empirical support to the impact of information campaigns and the increased importance given in the news to femicides. Notably, we find that the salience of the news and its impact on help-seeking behavior quickly fades away. To avoid this, the policy maker should promote recurrent information campaigns and public discussion around gender-based violence, together with active local support services for survivors aimed at increasing the expected benefits of calling for help. 


\section{Introduction}

The World Health Organization estimates that one in three women worldwide has suffered from physical and/or sexual violence in her lifetime (WHO, 2021). One in five women who have had at least one partner has experienced physical or sexual violence by an intimate partner (European Union Agency for Fundamental Rights, 2015). This makes intimate partner violence (IPV) one of the most frequent forms of violence against women. The most extreme form of violence against women is the gender-related murder of a woman by a man, or femicide. This is not an uncommon phenomenon: in 2017, 87,000 women in the world were intentionally killed, and in $58 \%$ of the cases the perpetrator was either a current or former intimate partner, or a family member (Stöckl et al., 2013; UNODC, 2018).

In this paper, we study the drivers that lead survivors of intimate partner violence to seek for help. Specifically, we use two unique high-frequency databases containing geo-localized information on femicide events and on the calls to the Italian national antiviolence helpline, and we investigate whether the news about femicides trigger more calls to the helpline.

Evidence from Italy is instructive because the Italian figures on IPV violence and the policies implemented to fight it are comparable to the worldwide ones. About $31 \%$ of women aged 16 to 70 have suffered from physical or sexual violence at least once in their life (ISTAT, 2021b). The male-to-female sex ratio among victims of voluntary manslaughter has decreased from around 5 to one in the early $1990 \mathrm{~s}$, to 1.6 to one in $2018 .^{1}$ In 2018 , $80 \%$ of women were murdered by a current or former partner, or by a family member (55\% and 25\%, respectively, ISTAT, 2020). The policies implemented in Italy to prevent gender-based violence, protect the survivors, and prosecute the offenders are aligned to those implemented worldwide. ${ }^{2}$ Among them there is the creation of a dedicated national service. Promoted by the Italian Government, the 1522 helpline provides support and information about shelters and related services for survivors of intimate partner violence. The service is available 24 hours a day / 7 days a week and can be accessed anonymously.

Due to data availability, in the main analysis we consider data on calls and femicides over the period January-May in the years 2015-2019. We match province-level weekly

\footnotetext{
${ }^{1}$ This result is due to a decreasing trend in the homicides of men which was not paralleled by the trend of women murdered, whose number has been fairly stable over the past decades.

2 At least 155 countries have passed laws on domestic violence (World Bank, 2020). See the UN Women's Global Database on Violence Against Women, available at https://evaw-global-database. unwomen.org/en for an overview of $\mathrm{n}$ policies and campaigns implemented in different countries worldwide.
} 
information of the calls to the 1522 helpline with detailed information about femicide events, and we exploit the timing of femicide news at the local level to study whether they trigger an increase in helpline calls, i.e., whether they boost help-seeking behaviour. To mitigate concerns about the potential correlation of the news with the prevalent level of violence, we adopt a difference-in-differences design. To capture temporal and geographical heterogeneity, the empirical model includes week dummies and province fixed effects.

We find that helpline calls increase by nine percentage points, which corresponds to a $21 \%$ increase. The effect is detectable in the week after the femicide is reported in the news and in the province where the femicide has occurred. Our results are robust to the inclusion of province-specific linear trends based on past violence, poverty and literacy, to week-region-year fixed effects specifications, to the use of a Poisson's pseudo log-likelihood model, and to the estimation method proposed by Imai et al. (2021), which allows to take into account that treated units may switch in and out of the treatment. Two placebo exercises, based on future femicides and on murders motivated by terminal illnesses or severe disability, which we expect to be unrelated to IPV, lend support to the finding that the helpline calls specifically respond to the femicide news.

In an additional heterogeneity analysis, we also show that information about the type of weapon used by the killer is not a significant driver of the helpline calls. Moreover, we show that the intensity of Google searches, which proxies for the general interest and curiosity about a specific femicide and, possibly, the corresponding media coverage, does not seem to play a major role in the help-seeking behaviour.

To help interpreting the empirical results, we propose a theoretical model where an IPV survivor contemplates whether to seek for help after receiving the news of a femicide. We assume that femicide news make future IPV more salient to the survivor, both in case no action is taken by the survivor, and also in case she calls the helpline, as this may trigger retaliation and additional violence from the offender. We show that the decision to call depends on whether the news increase the expectation of future violence more in the former than in the latter case, and that the responsiveness to the news increases when the expected benefits of calling the helpline and escaping violence are higher.

By showing that reporting femicide news is effective at triggering help-seeking behavior for survivors, our results contribute to understanding what policy tools can be implemented to address intimate partner violence. For example, Aizer and Dal Bo (2009) show that the introduction of no-drop laws leads to increased help-seeking behaviour, and Chin and Cunningham (2019) show that laws allowing for the officer discretion to arrest 
are associated with a lower number of intimate partner homicides. Amuedo-Dorantes and Deza (2019) demonstrate that sanctuary policies, that limit the co-operation of law enforcement agencies with federal immigration authorities, induce a decrease in femicides among Hispanic women in the US. Iyer et al. (2012) find that higher female representation in the local governments is associated to a rise in help-seeking by survivors of gender-based crimes, and Miller and Segal (2019) document higher rates of IPV reporting when the female representation among police officers increases. Levy and Mattsson (2020) show that the reporting gender-based violence and abuse has increased following the \#MeToo movement, which is consistent with the idea that heightened public awareness boosts the credibility of the reports, and decreases the uncertainty about the consequences and fear of retaliation (Lee and Suen, 2020; Cheng and Hsiaw, 2020).

This paper also contributes to understanding the drivers of gender-based violence, which have been recently investigated by, e.g., Yilmaz (2018), Tur-Prats (2019), González and Rodríguez-Planas (2020), Angelucci and Heath (2020), and Tur-Prats (2021). By focusing on the drivers of the IPV survivors' response, we provide a complementary perspective to the literature studying crime and the impact of exposure to the media, which typically focuses on the drivers of the offenders' response. For example, Dahl and DellaVigna (2009) find that violent crime decreases on days with larger theater audiences for violent movies. With specific reference to domestic violence, Card and Dahl (2011) exploit results of football games broadcast and show a rise in IPV violence after an upset loss, while Jensen and Oster (2009) find that the introduction of cable television in India is associated to significant decreases in the acceptability of domestic violence towards women. ${ }^{3}$ Our paper adds to this literature by showing that help-seeking behavior from victims of IPV is a specific response to the news of a femicide - and not to any news about non-IPV related murders - and that the intensity of the media coverage has a negligible impact.

The remainder of this paper is structured as follows: Section 2 describes the context and the data. Section 3 introduces the theoretical framework, while Section 4 outlines our empirical approach. Section 5 describes our findings. Section 6 offers some concluding remarks.

\footnotetext{
${ }^{3}$ For a comprehensive review of the economic impact of exposure to the media, see DellaVigna and La Ferrara (2015).
} 


\section{Helpline calls and femicides in Italy}

To address our empirical research question, we use two unique sources of data. The first one is a novel administrative province-level database, provided by the Department for Equal Opportunities of the Italian Government, which collects the weekly number of calls to the 1522 helpline covering the period January 1-May 31 for the years 2015-2019. The second one is a geolocalized high-frequency dataset on killings of girls and women compiled by the Italian non-governmental organization Casa delle Donne per Non Subire Violenza, which is specialized in providing support and shelter for women who undergo violence. ${ }^{4}$

The 1522 helpline is the national hotline aimed at helping victims of gender-based violence and stalking in Italy. Created in 2006, it is a free service available 24/7 in five languages. Specialized operators offer support to victims of violence and stalking and act as the first contact point for anti-violence centres and shelters. This was the case for three out of four calls in 2019, making the 1522 helpline the first step out of violence for most victims (ISTAT, 2021a). This service is especially relevant because survivors of domestic violence tend to press charges only once they find refuge in a safe place. ${ }^{5}$

Table 1: Calls to the 1522 helpline by reason and identity of the caller, 2019

\begin{tabular}{|c|c|c|c|c|}
\hline \multirow[t]{2}{*}{ Reason } & \multirow[t]{2}{*}{ Calls in 2019} & \multicolumn{3}{|c|}{ of which: } \\
\hline & & $\begin{array}{l}\text { made for } \\
\text { oneself }\end{array}$ & $\begin{array}{c}\text { made by } \\
\text { family/friends }\end{array}$ & $\begin{array}{c}\text { made by } \\
\text { professionals }\end{array}$ \\
\hline Request for information & $10,816(50.8 \%)$ & $95 \%$ & $1 \%$ & $4 \%$ \\
\hline Request for help: violence & $6,483(30.5 \%)$ & $100 \%$ & $0 \%$ & $0 \%$ \\
\hline Reporting of violence & $1,098(5.2 \%)$ & $29 \%$ & $67 \%$ & $4 \%$ \\
\hline Request for help: stalking & $897(4.2 \%)$ & $100 \%$ & $0 \%$ & $0 \%$ \\
\hline Emergency & $174(0.8 \%)$ & $100 \%$ & $0 \%$ & $0 \%$ \\
\hline Other & $1,822(8.6 \%)$ & $100 \%$ & $0 \%$ & $0 \%$ \\
\hline Total & $21,290(100 \%)$ & & & \\
\hline
\end{tabular}

Note: Request for information includes information on the service, on national anti-violence centres, legal information, information on procedures from professionals and on the legal responsibilities of public operators; Other includes reporting of malfunctioning services, misleading media coverage and calls out of target. Source: ISTAT (2021a).

${ }^{4}$ The NGO is aimed at supporting women who have suffered violence or have been threatened. Women can find hospitality, general information, legal advice, emergency houses and safe places, and support for parenting.

${ }^{5}$ In 2019, there were 302 active anti-violence centres in Italy. They typically operate at the local level and offer services such as counselling (92.2\% of them), legal support (93.8\%), job search support (80.5\%), support for parenting (62.3\%), shelters (66.5\%) and emergency first aid (58.8\%). Police and social services are usually involved only in extreme cases (ISTAT, 2019). 
Every year the 1522 helpline receives more than 20,000 calls. Typically, 30\% of the calls consist of requests for help from victims of violence, while about $50 \%$ seek information on anti-violence centers or on the services provided by the helpline (Table 1). The large majority of calls requesting information are from users who call for themselves, which confirms that the helpline is an important tool for victims wanting to escape from violence. About $5 \%$ of calls report violence. In 2 cases out of 3 these calls are made by the victims' relatives (parents, siblings, or children) or friends. The information disclosed on the aggregated data for 2019 also reveals that the offender is usually a current or former partner (79\% of cases) or a family member (13\%), making even more difficult escaping abusing situations, and that $92 \%$ of the calls refer to reiterated episodes of violence (ISTAT, 2021a). ${ }^{6}$

Panel (a) of Figure 1 presents the geographical distribution of the average weekly number of calls per 100,000 inhabitants in the period January-May in 2015-2019 by province. The map shows the existence of differences in the use of the helpline both

Figure 1: Calls to the 1522 helpline and femicides, January-May 2015-2019

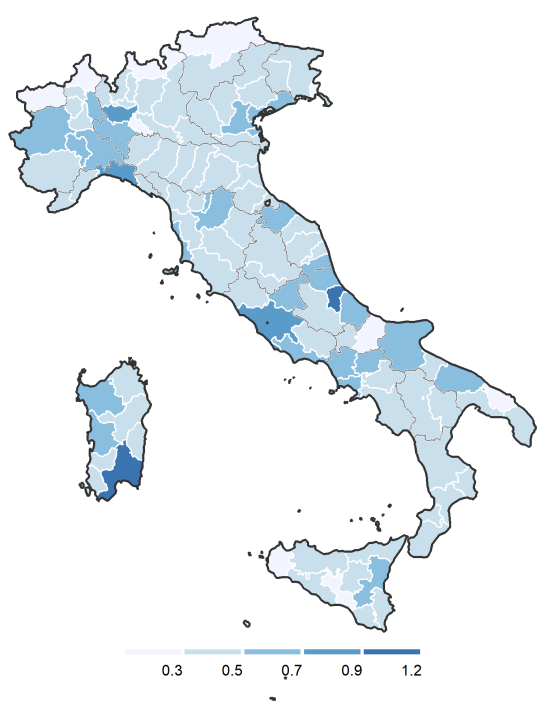

(a) Calls to the 1522 helpline

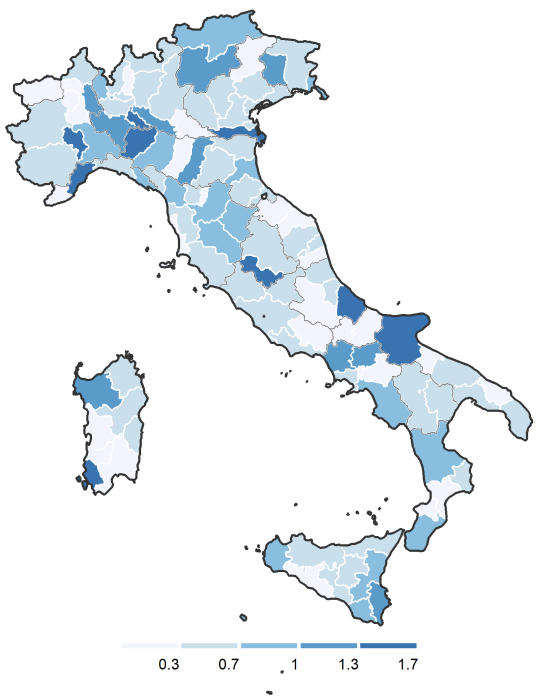

(b) Femicides

Note: The legends report $(a)$ the average weekly number of calls per 100,000 inhabitants and $(b)$ the total number of femicides per 100,000 inhabitants in the period January-May 2015-2019 for each province. Grey and white lines refer to regional (NUTS-2) and province (NUTS-3) boundaries, respectively.

\footnotetext{
${ }^{6}$ Information on the reasons for calling and on the identity of the user or offender are only available since year 2018, and only at the national level. Hence they cannot be used in our empirical analysis. The disaggregation shown in Table 1 is similar when considering year 2018. Since year 2020 is an outlier, due to the Covid-19 pandemic, it is not considered in our analysis.
} 
across the 109 provinces and across the 20 Italian regions. We merge the high-frequency data on helpline calls with the novel dataset on femicides. This detailed database records murders of girls and women reported by the local and national press in Italy. It includes information on the date of each event, the municipality in which the murder occurred, the type of weapon used, the relationship between the survivor and the offender, and some personal characteristics such as age, nationality, job occupation, history of violence, illness, use of substances. ${ }^{7}$

A major advantage of this dataset is the rich information about gender-based homicides, which is otherwise unavailable in the official figures provided by the Italian Institute of Statistics (ISTAT) and the police. ${ }^{8}$ Accordingly, we can distinguish among different types of murders involving females, based on the motive for each assassination. This piece of information is crucial to our analysis, as it allows to distinguish between femicides and

Figure 2: Number of female homicides by year

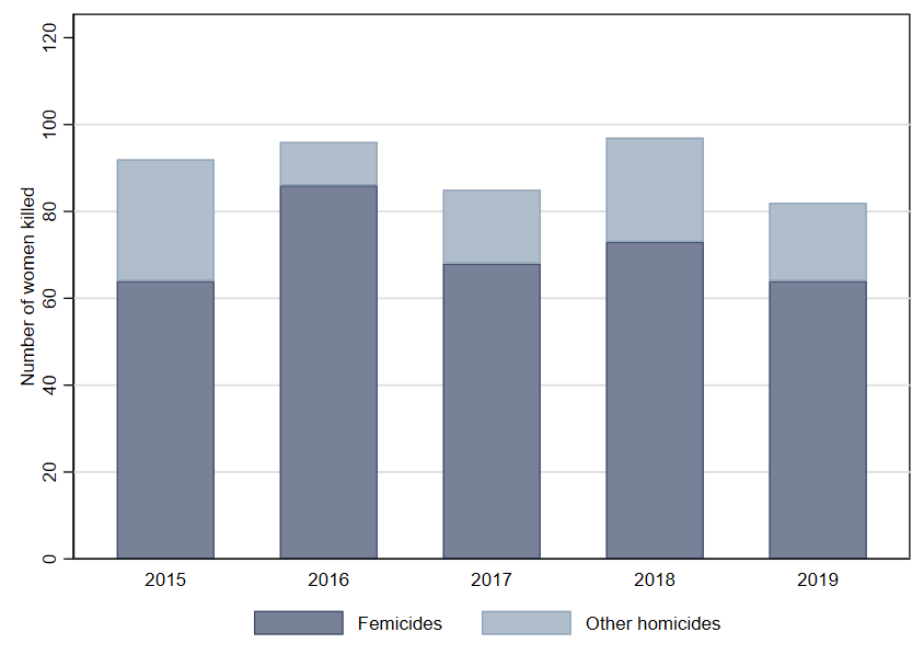

Note: Total number of female homicides by year. Dark blue bars indicate femicides; Light blue bars indicate non gender-related female homicides due to, e.g., depression, health reasons or disability of the victim or her relatives.

7 The database is compiled by the Casa delle Donne per Non Subire Violenza NGO's activists and the collection of data is based on a broad definition of femicide that includes all the killings of women and girls that occurred for reasons of gender (Casa delle Donne per Non Subire Violenza, 2019). The dataset is based on information publicly available in the national and local newspapers.

${ }^{8}$ Due to differences in the classification criteria, ISTAT counts of female homicides are sometimes slightly different from ours. This can potentially introduce some measurement error. Nevertheless, when comparing the aggregate number of voluntary manslaughter with female victims registered by ISTAT and the events in our sample, we do not observe substantial differences. For instance, in 2018 ISTAT reports 133 episodes, while our data reports 115 records (ISTAT, 2020). 
other homicides where the victim is a woman, but the motive is unrelated to IPV stricto sensu. ${ }^{9}$ The first group encompasses murders where the woman was killed by her current or former partner or by someone else for reasons associated with a sentimental or sexual relationship. The second category includes all homicides where the motive is related to the health conditions of the murderer, the victim, or her relatives. Most of these homicides are ascribable to the existence of a severe disability, terminal illnesses or depression, and often involve elderly women. ${ }^{10}$

Based on this classification, Figure 2 describes the number of women killed each year. Over the period 2015-2019, the homicides where the victim is a woman are slightly less than 100 per year. Most are femicides, while around a fifth are prompted by health reasons (i.e., other homicides). Figure A.1 shows the timeline of femicides, distinguishing between those considered in our sample and those occurring outside of our observation window (dark and light blue bars, respectively). Panel (b) of Figure 1 displays the geographical distribution of femicides by province in the period January-May in 2015-2019. As in the case of the calls to the 1522 helpline, no obvious geographical pattern emerges.

\section{Calling for help: a theoretical model}

To guide the interpretation of the empirical results, in this section we present a model that illustrates the decision problem of a survivor of intimate partner violence. ${ }^{11}$

Consider the choice between two options: calling or not calling the helpline. After the choice is made, two alternative rankable states of the word can realize. The preferred outcome is called the good state, and the alternative outcome is the bad state. At time $t$, the survivor expects the bad state to occur with subjective probability $p$ if the helpline is called, and with subjective probability $q$ if she does not call (Figure 3).

If the helpline is called, the survivor obtains $B \geq 0$ and $-V<0$, depending on whether the good or the bad state is realized, respectively. For later reference, it is useful to think to the good state as a situation that produces net benefits from calling the helpline, which range from the benefits of psychological counseling to the possibility of escaping

\footnotetext{
${ }^{9}$ We adopt the notion of femicide as the intentional murder of women because of their gender. This notion is not undisputed, as broader definitions can include any intentional murder of women and girls (see, e.g., WHO, 2012).

${ }^{10}$ We exclude from our analysis a residual category of a few events $(n=29)$ that are attributable to unrelated motives such as robberies, or when the motive is unknown and the murderer is not a former or current partner. When including these events among the femicides, the results do not change.

11 The model can potentially describe also the decision problem of an altruistic person (e.g. a relative or a friend) who cares about the wellbeing of the IPV survivor. For expositional simplicity, in the text we refer to the IPV survivor only.
} 
Figure 3: Calling the helpline

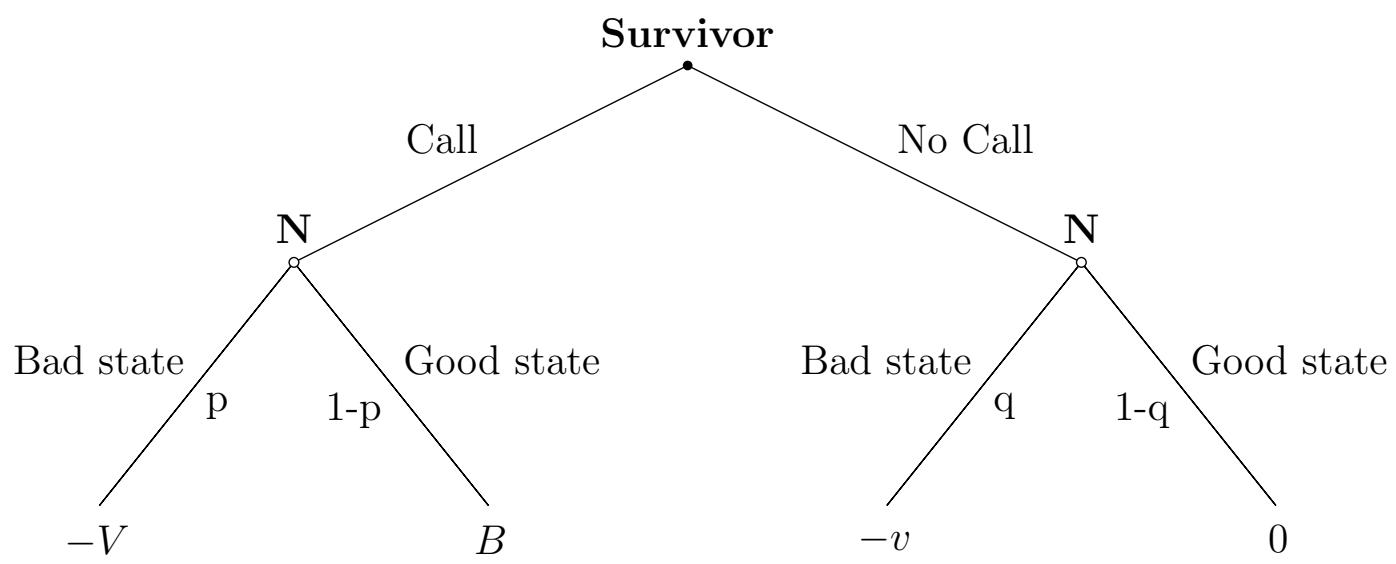

violence altogether. These benefits are not only individual-specific, but they also depend on targeted policies implemented at both the national and the local level, such as the availability of helplines and shelters. The bad state represents a scenario in which calling the helpline entails undesirable consequences due to, e.g., additional violence as a possible retaliation by the offender. Accordingly, in the following we will refer to $B$ as the benefit of escaping, and to $V$ as the level of violence-as-retaliation.

If the helpline is not called, the survivor receives $-v<0$ if the bad state is realized, and zero otherwise. Here the bad state describes, e.g., a situation in which violence persists. Accordingly, we will refer to $v$ as the level of status-quo violence. The good state describes a situation in which violence is reduced, or even ceases, even if the survivor does not call for help. ${ }^{12}$

Under risk neutrality, the options of calling and not calling yield the following expected utility, respectively,

$$
\begin{aligned}
& U(\text { Call })=(1-p) B-p V \\
& U(\text { No Call })=-q v .
\end{aligned}
$$

By comparing the two expected payoffs, a survivor that expects a level of violence $v$ in the status-quo will call the helpline if

$$
v>\hat{v} \equiv \frac{p V-(1-p) B}{q}
$$

12 These labels are an oversimplification introduced for expositional reasons, and they are not meant to exhaustively describe the variety of factors that affect the payoffs associated to the states of the world realized after calling or not calling the helpline. 
where $\hat{v}$ denotes a threshold level of expected violence in case no action is taken.

Proposition 1. Survivors call the helpline if the level of violence expected in case no call is made is above threshold $\hat{v}$

The above Proposition delivers the intuitive notion that a survivor that expects future violence in the status quo to be unbearable, i.e. above the threshold $\hat{v}$, will call the helpline. As shown in equation 3, threshold $\hat{v}$ depends on the level of violence as retaliation $V$, on the benefits of escaping violence $B$ and on the expected probabilities of violence in the bad state $(p$ and $q)$.

To account for heterogeneity, let the expected probabilities of violence, and the expected level of violence and benefits be individual-specific. This implies that expected future violence in the status quo, $v_{i}$, and the threshold $\hat{v}_{i}$ are heterogeneous across survivors. Denoting with $f\left(v_{i}, \hat{v}_{i}\right)$ the joint distribution of $v_{i}$ and $\hat{v}_{i}$ in the population, the proportion of survivors that call the helpline is given by the double integral $\int_{0}^{\infty} \int_{\hat{v}_{i}}^{\infty} f\left(v_{i}, \hat{v}_{i}\right) d v_{i} d \hat{v}_{i}$. Accordingly, more survivors are expected to call the helpline if $\hat{v}_{i}$ decreases. Using equation 3 this occurs in the following cases. ${ }^{13}$

Remark 1. The number of calls to the helpline increase when the threshold level of violence in case no action is taken decreases. This occurs when

- The benefits of escaping $B_{i}$ are large,

- The level of violence as retaliation $V_{i}$ is small,

- The probability of violence as retaliation $p_{i}$ is small,

- The probability of violence in the status quo $q_{i}$ is large.

At a given time $t$, expectations about the future probability of violence can depend on personal information as well as on aggregate information. We assume that the subjective probability of a bad state at time $t$ depends on the set of news $N_{i, t}$ about violence the individual has come to know at time $t$, as well as on idiosyncratic factors, personal history and characteristics and geographic-specific factors $X_{i, t}$ :

$$
p_{i, t}=f\left(N_{i, t}, X_{i, t}\right), \quad q_{i, t}=g\left(N_{i, t}, X_{i, t}\right) .
$$

\footnotetext{
${ }^{13}$ In principle, the level of violence-as-retaliation $V_{i}$ can be related the status-quo level of violence so that, e.g, $V_{i}=R_{i} v_{i}$, with $R_{i}>1$. In such a case, calling the helpline is still more likely if the benefits of escaping $B_{i}$ are large, if the probability of violence in the status quo $q_{i}$ is large, and if the "retaliation factor" $R_{i}$ is small enough, i.e. (omitting the subscipts) if $1<R<B(1-p) /(p v)+q / p$.
} 
Taking $X_{i, t}$ as given, it seems reasonable to assume that the release of femicide news in a given area depends on the average probability of violence and on the average level of violence,

$$
N_{i, t}=f\left(\bar{p}_{t}, \bar{q}_{t}, \bar{v}_{t}, \bar{V}_{t}\right)+\varepsilon_{t}
$$

and that femicide news $n_{i, t} \in N_{i, t}$ increase the individual expectation of future violence in IPV survivors through an increase in the subjective probabilities $p$ and $q$.

$$
p^{\prime} \equiv \frac{\partial p_{i, t}}{\partial n_{i, t}} \geq 0, \quad q^{\prime} \equiv \frac{\partial q_{i, t}}{\partial n_{i, t}} \geq 0 .
$$

The assumption can be justified with the hypothesis that the femicide news increases the salience of future expected violence in the bad states due to, e.g. an emotional identification with the victim, or fear of being subject to additional violence.

The effect of femicide news on the decision to call can be assessed by considering how it affects the threshold $\hat{v}_{i, t}$ :

$$
\frac{\partial \hat{v}_{i, t}}{\partial n_{i, t}}=\frac{\left(B_{i, t}+V_{i, t}\right) p^{\prime}-\hat{v}_{i, t} q^{\prime}}{q_{i, t}} .
$$

where $\hat{v}_{i, t}$ is defined in 3 . If expression 7 is negative, a femicide news reduces the threshold required for choosing to call, which implies a higher likelihood of calling at the aggregate level. Since $p^{\prime}$ and $q^{\prime}$ are non negative, however, the sign of the expression is in general ambiguous, because of two opposite mechanisms. The first one is due to increased expectations of violence-as-retaliation. To see it, suppose $q^{\prime}=0$ : the femicide news only increases $p$ (the probability of retaliation), but it does not affect expected violence in the status quo. In such a case, the news induces less IPV survivors to call because of the increased expectation of violence as retaliation. The second mechanism is due to increased expectations of violence in the status quo. Suppose $p^{\prime}=0$ : the news does not affect the probability of retaliation, but it increases the expectation of violence in the status quo. Accordingly, the threshold $\hat{v}$ becomes smaller and more survivors will call the helpline.

When both channels are active, the overall effect depends on which of the two mechanisms is dominant:

Remark 2. After a femicide is reported in the news, more survivors call the helpline if the motives driven by increased expectations of violence in the status quo dominate the increased expectations of violence-as-retaliation.

Note that that the responsiveness of the threshold to the femicide news -and consequently of the decision to call the helpline- increases when the benefits $B$ of escaping are 
larger. $^{14}$

\section{Empirical Strategy}

Empirically testing the implications of the theoretical model outlined in the previous section requires identifying the statistical relationship between femicide news in a given area and helpline calls in the same area.

A possible endogeneity concern is that, irrespective of the femicide event and its media coverage, the occurrence of a femicide can depend on the local prevalence of violence, as shown in equation 5. If this is the case, a simple OLS would deliver biased estimates. Exploiting within-province variation in the very short run, i.e., weeks before and after the treatment, helps addressing this concern and accounting for the unobserved aggregate prevalence of violence at the local level. Accordingly, we adopt a regression differencein-differences setting where the treatment of interest is the release of a femicide news occurred in province $p$ in week $t$. We include in our main specification also leads and lags of the release of femicide news. This event-study design can be formalized as follows (Athey and Imbens, 2021):

$$
Y_{p t}=\alpha+\sum_{\pi=-4}^{-1} \beta_{\pi} D_{p t+\pi}+\sum_{\tau=1}^{4} \beta_{\tau} D_{p t+\tau}+\delta_{t}+\gamma_{p}+\epsilon_{p t}
$$

The outcome $Y_{p t}$ is the number of calls to the 1522 helpline per 100,000 resident population measured in province $p$ in week $t$. The dummies $D_{p t+\pi}$ and $D_{p t+\tau}$ describe 4 pre- and 4 post-treatment periods associated to each femicide. Figure A.2 displays the time and geographical variation of our treatment (femicide). In the Figure, provinces are ordered by population size. As expected, femicides occur more frequently the more populated the area, such as in the provinces of Rome (RM), Naples (NA) and Milan (MI). Given that there may be repeated events in a given province $p$, we consider a 16-week window around each event. Thus, the dummies associated to $\pi=-4$ and $\tau=4$ include all periods prior to $t-4$ (up to $t-8$ ) and those after $t+4$ (up to $t+8)$, respectively. ${ }^{15}$ The terms $\delta_{t}$ and $\gamma_{p}$ allow for week and province fixed effects, respectively, while $\epsilon_{p t}$ is the error term.

In the main analysis, model 8 is estimated using standard errors clustered at province level, with the week before a femicide occurs, i.e. week $t-1$, as baseline time period.

\footnotetext{
14 To see it, note that $\partial^{2} \hat{v} /(\partial n \partial B)=p^{\prime} / q+(1-p) q^{\prime} / q^{2}>0$.

15 Robustness exercises based on different values of $\pi$ provide similar conclusions.
} 
Our identification strategy is grounded on the assumption that provinces where femicides occur, and provinces that do not experience such events follow a parallel trend in the pre-treatment period, i.e., in the weeks prior to the femicide. If this is the case, we can, to some extent, trust that in these areas femicides are not endogenously related to differential trends of violence. Empirically, the parallel trend assumption is satisfied if the lead coefficients $\beta_{\pi}$ are not statistically different from zero, which implies that the treated provinces are trending similarly to the untreated ones before the femicide. Under the above assumptions, the lag coefficients $\beta_{\pi}$ measure the effect of a femicide news on helpline calls in the weeks following the event.

Our results are robust to concerns related to the possible existence of geographical spillovers across provinces. From an econometric point of view this is relevant because, if there are geographical spillovers, the Stable Unit Treatment Value Assumption (SUTVA) does not hold and the estimated effects are likely to be downward biased. Checking whether the SUTVA holds is also informative from a descriptive point of view, because it give a better understanding of the geographical reach of the effect of a femicide news on salience about IPV and help-seeking behavior.

An additional concern may arise if calls to the 1522 helpline respond specifically to a femicide, or whether they are affected by any news about the killing of a woman, even if unrelated to gender-based violence. To address this concern, we run an falsification analysis using as a trigger the occurrence of female homicides that are not considered to be femicides, such as those driven by health reasons. To further examine the causal effect of femicide news on help-seeking behavior, we perform a randomization inference exercise where we consider future femicides, i.e. the those occurred in the second half of each year. These femicides are not considered in the main analysis, because the helpline calls database only covers the January-May period. However, by matching each femicide occurred in the weeks 23-45 (shown as light blue squares in Figure A.2) with helpline calls over the weeks 1-22 in the same province-year, it is possible to perform a falsification test and check whether the causal link found in the main analysis disappears, as expected.

We consider also three robustness check exercises. Given the availability of highfrequency data at province-week level, the event-study design already helps to mitigate possible issues related to unmeasured controls. However, as a further robustness check, we run an additional analysis by including province-specific linear differential trends in pre-existing levels of violence, poverty, and education. Moreover, following the recent empirical developments in the difference-in-difference literature, we run an analysis that explicitly allows treated units to switch in and out of the treatment, in the spirit of Imai 
et al. (2021). We also address potential incidental parameters issues by estimating a Poisson's pseudo log-likelihood model. As shown in the next section, all three exercises deliver estimated coefficients in line with the main results.

Finally, we study whether the type of weapon used for the femicide is related to help-seeking. The working hypothesis is that the type of weapon can be a proxy of the brutality of the murder, which may affect the IPV survivor's response and typically produces a wider media coverage. Unfortunately, information about the media coverage of femicides is not available. However, we can use Google search data as a proxy of the general interest about a specific femicide. If Google searches are correlated to the media coverage, it is possible that femicides that have raised more interest from internet users, and have probably received more attention by the media, can predict a stronger response by IPV victims.

\section{Results}

Figure 4 shows the effect of the release of news about the occurrence of a femicide on the 1522 helpline calls. The estimated coefficients, also reported in column 1 of Table A.1 imply a 9 percentage points increase in helpline calls in the week following the occurrence of a femicide, i.e., at $t+1$. Given an average value of 0.44 calls per 100,000 population,

Figure 4: Helpline calls and femicides

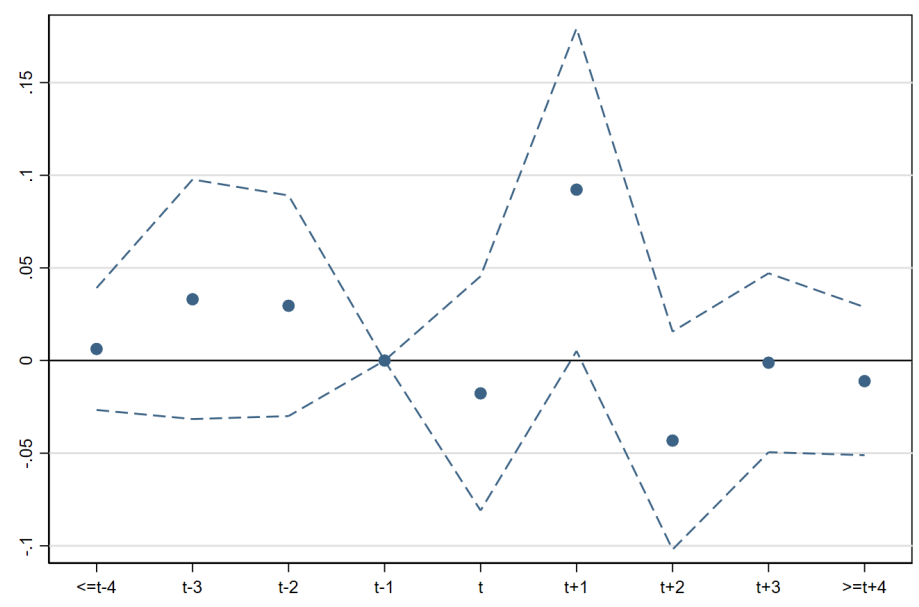

Note: OLS estimates (blue dots) of lags and leads and corresponding 95\% confidence intervals (dashed lines) as from Equation 8. The baseline period is $t-1$ (one week prior to the occurrence of a femicide). The dependent variable is the number of calls to the 1522 helpline per 100,000 population. Estimates include province and week-year fixed effects. Standard errors are clustered at province level. 
this corresponds to a $21 \%$ increase. The effect is positive and statistically significant, but it is short-lived, as the effect appears at $t+1$ and fades afterwards. Reassuringly, coefficients reveal no significant differences across treated and control provinces in the periods prior to the femicide, suggesting that the parallel trend assumption holds.

Following the theoretical model presented in Section 3, the increase in helpline calls is consistent with the hypothesis that femicide news increase future expectations of violence by women suffering from IPV, and in particular that the fear of increased violence in the status quo overcomes the fear of violence as a form of retaliation for calling the helpline.

The high frequency of our data helps controlling for both spatial heterogeneity and time shocks by including province and week-year fixed effects. This allows to exploit the within-province-week variation in the data. Nonetheless, other local characteristics might still be potentially correlated with the prevalence of violence and help-seeking behaviour from survivors. As robustness checks, in Table A.2, columns 1 to 3, we report the results of additional regressions in which we add province-specific linear differential trends in pre-existing levels of violence, poverty, and education, respectively. ${ }^{16}$ The inclusion of these controls is meant to absorb additional possible confounding factors, but it does not change our main conclusions. Similar results are shown in column 4, where we include province-year and week-region fixed effects to exploit the residual province-week-year variation within the same region. ${ }^{17}$ These fixed effects take into consideration potentially important confounding factors, such as changes in regulations enacted by regional entities and public funding to anti-violence centers. The results, however, do not change.

A notable feature of our setup is that the same unit can can be treated more than once over time. This may occur if in a province there are more than one femicide in the time horizon we are considering. To avoid this feature to bias our results, in columns 5 and 6 we consider only the first femicide occurred in a province as treatment and estimate a standard staggered difference-in-differences model. We consider two alternative cases. In column 5, we cut the sample right before the occurrence of the second event. In column 6, we retain our initial sample and consider a province as (always) treated after the occurrence of the first femicide in the province. ${ }^{18}$ Relatedly, following the recent developments in the difference-in-differences literature, we apply the approach proposed

\footnotetext{
${ }^{16}$ Violence, poverty and education are proxied by the total number of female homicides, the incidence of households in potential economic distress and the incidence of illiterates, respectively.

${ }^{17}$ The number of observations is reduced because the Valle d'Aosta region, which comprises a single province, is dropped from the sample.

${ }^{18}$ Although data on helpline calls cover the period January-June of each year, data on femicides are available for the entire year. This allows us to identify the fist time a given province becomes "treated" even outside the observation period available for our dependent variable.
} 
by Imai et al. (2021), which is based on matching and weighting methods to refine the comparison between treated and control units. ${ }^{19}$ Figure A.3 (left) illustrates that most matched control units present similar history as the treatment units. Figure A.3 (right) shows the matching estimates of the effects of femicides on help-seeking behavior. As in our main results, the point estimate is positive and statistically significant in period $t+1$ and not different from zero elsewhere.

In addition, we address potential incidental parameters issues, by estimating a Poisson's pseudo log-likelihood (PPML) model, which accounts for dependent variables with many zeros, different patterns of heteroskedasticity, and is robust to outcome measurement errors (Santos Silva and Tenreyro, 2006). As shown in column 7 of Table A.2, all estimated coefficients of the robustness checks are in line with the main results.

Finally, we conduct a series of falsification exercises in the spirit of placebo tests to strengthen the causal mechanism. We test the hypothesis of the failure of the SUTVA by including provinces adjacent to a treated unit to the treatment group. Figure A.4 excludes the existence of any spillover effect of the femicide news over the adjacent provinces. ${ }^{20}$ We can therefore conclude that the effect of femicide news on help-seeking behavior is positive, statistically significant, and local in space and time.

Then, we substitute our main treatment variable with a dummy taking value one when a woman is killed and the motive is ascribable to health reasons, namely when the offender is gravely depressed or when either the survivor, her children or her partner-killer suffer from terminal illnesses or severe disability. We do not expect this type of female homicide news to affect the propensity to call the anti-violence helpline because these murders are typically associated to situations of extreme disadvantage and distress, and are generally unrelated to gender-based violence. Consistent with this hypothesis, Figure 5 and Table A.1 (column 2) show that the coefficients associated to this specification are never statistically different from zero, and also that their magnitude is very small.

To address the possibility that the main results are driven by spurious correlations, we propose a randomization test based on future femicide, i.e., we exploit the falsified variation in the treatment displayed as light blue squares in Figure A.2. The coefficients related to this exercise, reported in Figure A.5, are small in magnitude and never statistically significant at any conventional level, thus alleviating concerns over the existence of a spurious relationship.

\footnotetext{
${ }^{19}$ Differently from other approaches commonly applied to difference-in-differences analyses (De Chaisemartin and d'Haultfoeuille, 2018; Callaway and Sant'Anna, 2021; Goodman-Bacon, 2021), this method better fits our setting because it foresees that units may switch in and out of the treatment.

${ }^{20}$ Extending the treatment at the regional level yields the same results.
} 
Figure 5: Helpline calls and female homicides attributable to health reasons

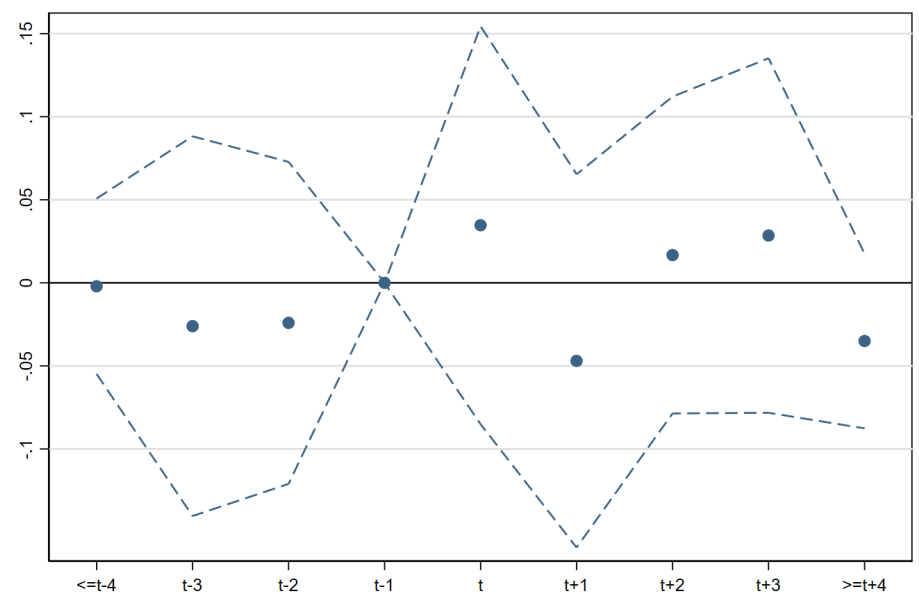

Note: OLS estimates of lags and leads and corresponding $95 \%$ confidence intervals as from Equation 8 . The baseline time period is $t-1$ (one week prior to the occurrence of a female homicide attributable to health reasons). The dependent variable is the number of calls to the 1522 helpline per 100,000 population. Estimates include province and week-year fixed effects. Standard errors are clustered at province level.

Since the effect of the news depends on the individual perception of the femicide news, as predicted by the model, we perform two additional exercises to understand the potential mechanisms driving our results. First, we consider information on the type of weapon used for the femicide, with the hypothesis that the more brutal the murder, the more extensive the news media coverage. We define four mutually-exclusive categories of weapon: firearm, fight (including any type of beating, pushing or strangling), knife or similar cutting objects, and other means (e.g., poison). The results are reported in columns 1 to 4 of Table A.3. The upper panel reports the set of coefficients associated to the occurrence of a femicide; the lower panel refers to the differential effect of the corresponding category. The main results continue to hold across specifications, but no difference in response to a particular type of murder is detected.

Second, we construct a measure of the interest of the general public for each femicide, as measured by web searches on Google regarding victim names for the year 2015-2019. Our hypothesis is that the most notorious cases might trigger a stronger take-up of helpline calls from survivors of IPV. We measure the intensity in interest using region-level Google queries containing the name of the victim fo the years 2015-2019, and we classify as most searched femicides those with average searches above the 75th percentile of the overall distribution in the four weeks following the murder. ${ }^{21}$

${ }^{21}$ The intensity of searches is retrieved from Google Trends (https://trends.google.com/trends/), 
Although the point estimate for the most searched femicides is twice as large as the main effect at week $t+1$, the coefficient is not statistically significant. This result does not seem to be due to lack of statistical power, given the large sample size of about 12 thousand observations. However, it is possible that the low precision of the estimate is a consequence of the fact that the Google search data are aggregated at the regional level, which comprises both treated provinces (for which the previous analysis has shown a significant effect) and untreated ones (for which there is no spillover effect). Given the current data availability, we conclude that, although suggestive, we are not able to corroborate the hypothesis that femicides that have attracted more interest from the general public, and are likely to have received more media coverage, significantly affect help-seeking behavior by IPV survivors.

\section{Discussion and conclusions}

Violence against women is a violation of human rights (Council of Europe, 2011). Not only it produces consequences on the survivors' physical and mental health, but it also hampers female autonomy and self-realization. Femicides are the extreme realisation of a much more common phenomenon of violence perpetrated against women. In the EU, $33 \%$ of women have been physically or sexually abused since the age of 15 .

In this paper, we shed light on the help-seeking behaviour of survivors of intimate partner violence (IPV). We study how victims of IPV react to the news of a femicide by estimating whether it triggers calling a helpline and reaching out for help and support. Our theoretical model points to two opposite mechanisms. On one hand, the news might foster help-seeking by increasing the victims' expectations about future violence if no action is taken, or by raising the expected benefit associated with help-seeking. On the other hand, the femicide news might reduce the helpline calls if they increase the fear of retaliation by the violent offender.

To empirically test the effect of the news, we adopt a difference-in-differences design to estimate the degree to which IPV survivors seek help after a femicide is reported in the news. We use two unique data sources containing geo-localized information on calls to the Italian anti-violence helpline and femicide events over the period January-May in

which provides data on the search requests made through the Google search engine. Google Trends provide search results normalized by time (either daily, weekly or monthly) and by geographical area (either country or NUTS-2 level). The daily intensity of search in a geographical region is scaled on a 0-100 range, where 100 is attributed to the day featuring the most popular search over the selected time horizon and geographical unit. 
the years 2015-2019.

We find that after a femicide is reported in the news, calls to the helpline increase by about nine percentage points, which corresponds to a $21 \%$ increase in calls. The effect appears to be short-lived, and geographically localised. These findings are consistent with the femicide news increasing the survivor's expectations about future IPV. In the theoretical model we have presented, such expectations concerning the realization of a bad state of the world can occur either when calling or not calling the helpline. In the former case, they would be associated to the perpetuation of a status quo of violence, which can become more likely, or more salient, after the femicide news. In the latter case, they would be associated to the fear of undesirable consequences after the helpline has been called. The empirical evidence suggests that the first outcome, related to an increased expectation of future violence in case no action is taken, becomes more salient than the alternative mechanisms hindering help-seeking, such as the fear of retaliation.

The main policy implication of our findings is that talking about femicides not only raises awareness about the existence of violence against women, but it is also an important trigger for help-seeking behavior by the survivors of intimate partner violence. This is commonly recognized as an important step to end intimate partner violence, and our paper provides empirical support to the impact of information campaigns and the increased importance given in the news to femicides. Notably, we find that the salience of the news and its impact on help-seeking behavior quickly fades away. To avoid this, the policy maker should promote recurrent information campaigns and public discussion around gender-based violence, together with active local support services for survivors aimed at increasing the expected benefits of calling for help.

The result that the increase in the calls is detectable only in the province in which the femicide has occurred is consistent with different, non-mutually exclusive explanations. Here we consider two possible candidates: emotional identification with the victim, and saliency. The former hypothesis is more likely if geographical proximity helps the IPV survivor to identify with the victim, which in turn would trigger help-seeking. The second hypothesis suggests that the femicide news becomes particularly salient at the local level because it is more likely that someone in the community personally knows the victim or the killer, that the local media may provide additional coverage, and that the femicide triggers local manifestations and discussions that raise awareness about IPV. Due to privacy reasons, the characteristics of the callers are not available in the helpline database, which prevents us from testing the emotional identification hypothesis. The saliency hypothesis can be addressed using data on Google searches, which measures the amount 
of attention from the general public. Our results do not falsify this hypothesis, but they do not support it either. This may be due to the fact that the geographical cells described by the Google search data are too large and the information on Google searches not precise enough to detect an effect. Further investigation is needed to test whether the above hypothesis are reasonable explanations of the empirical results results reported in this paper.

\section{References}

Aizer, A. and P. Dal Bo (2009). Love, hate and murder: Commitment devices in violent relationships. Journal of Public Economics 93(3-4), 412-428. 5

Amuedo-Dorantes, C. and M. Deza (2019). Can sanctuary polices reduce domestic violence? IZA Discussion Paper 12868. 6

Angelucci, M. and R. Heath (2020). Women Empowerment Programs and Intimate Partner Violence. AEA Papers and Proceedings 110, 610-614. 6

Athey, S. and G. W. Imbens (2021). Design-based analysis in difference-in-differences settings with staggered adoption. Journal of Econometrics. 14

Callaway, B. and P. H. Sant'Anna (2021). Difference-in-differences with multiple time periods. Journal of Econometrics 225(2), 200-230. 18

Card, D. and G. B. Dahl (2011). Family violence and football: the effect of unexpected emotional cues on violent behavior. The Quarterly Journal of Economics 126(1), 103143. 6

Casa delle Donne per Non Subire Violenza (2019). I femicidi in italia: dati raccolti sulla stampa 2015-2018. https://femicidiocasadonne.wordpress.com. 9

Cheng, I.-H. and A. Hsiaw (2020). Reporting sexual misconduct in the \# metoo era. American Economic Journal: Microeconomics forthcoming. 6

Chin, Y.-M. and S. Cunningham (2019). Revisiting the effect of warrantless domestic violence arrest laws on intimate partner homicides. Journal of Public Economics 179, 104072. 5 
Council of Europe (2011). Convention on preventing and combating violence against women and domestic violence. Council of Europe Treaty Series-No. 210. 20

Dahl, G. and S. DellaVigna (2009). Does movie violence increase violent crime? The Quarterly Journal of Economics 124(2), 677-734. 6

De Chaisemartin, C. and X. d'Haultfoeuille (2018). Fuzzy differences-in-differences. The Review of Economic Studies 85(2), 999-1028. 18

DellaVigna, S. and E. La Ferrara (2015). Economic and social impacts of the media. In Handbook of media economics, Volume 1, pp. 723-768. Elsevier. 6

European Union Agency for Fundamental Rights (2015). Violence against women: an EU-wide survey. Main results. Technical report, Publications Office of the European Union. 4

González, L. and N. Rodríguez-Planas (2020). Gender norms and intimate partner violence. Journal of Economic Behavior \& Organization 178, 223-248. 6

Goodman-Bacon, A. (2021). Difference-in-differences with variation in treatment timing. Journal of Econometrics. 18

Imai, K., I. S. Kim, and E. Wang (2021). Matching methods for causal inference with time-series cross-sectional data. American Journal of Political Science forthcoming. 5, $15,18,28$

ISTAT (2019). Rilevazione sulle prestazioni e i servizi offerti rispettivamente dai centri antiviolenza e dalle case rifugio.

https://www. IstitutoNazionalediStatistica.it/it/files//2020/10/

Report-centri-antiviolenza-28102020-1.pdf. 7

ISTAT (2020). Homicide victims.

https://www. IstitutoNazionalediStatistica.it/en/archivio/243192. 4, 9

ISTAT (2021a). The helpline 1522 during the pandemic (quarterly data at q1 2021). https://www.IstitutoNazionalediStatistica.it/en/archivio/258904. 7, 8

ISTAT (2021b). Violence against women.

https://www. IstitutoNazionalediStatistica.it/en/violence-against-women. 4 
Iyer, L., A. Mani, P. Mishra, and P. Topalova (2012). The power of political voice: women's political representation and crime in india. American Economic Journal: Applied Economics 4(4), 165-93. 6

Jensen, R. and E. Oster (2009). The power of tv: Cable television and women's status in india. The Quarterly Journal of Economics 124(3), 1057-1094. 6

Lee, F. X. and W. Suen (2020). Credibility of crime allegations. American Economic Journal: Microeconomics 12(1), 220-59. 6

Levy, R. and M. Mattsson (2020). The effects of social movements: Evidence from\# metoo. Available at SSRN 3496903. 6

Miller, A. R. and C. Segal (2019). Do female officers improve law enforcement quality? effects on crime reporting and domestic violence. The Review of Economic Studies 86(5), 2220-2247. 6

Santos Silva, J. and S. Tenreyro (2006). The log of gravity. The Review of Economics and Statistics 88(4), 641-658. 18

Stöckl, H., K. Devries, A. Rotstein, N. Abrahams, J. Campbell, C. Watts, and C. G. Moreno (2013). The global prevalence of intimate partner homicide: a systematic review. The Lancet 382(9895), 859-865. 4

Tur-Prats, A. (2019). Family types and intimate partner violence: A historical perspective. Review of Economics and Statistics 101(5), 878-891. 6

Tur-Prats, A. (2021). Unemployment and intimate partner violence: A cultural approach. Journal of Economic Behavior \& Organization 185, 27-49. 6

UNODC (2018). Global Study on Homicide. Gender-Related Killing of Women and Girls. Vienna: United Nations Office on Drugs and Crime. 4

WHO (2012). Understanding and addressing violence against women: Intimate partner violence. Geneve: World Health Organization. 10

WHO (2021). Violence against women prevalence estimates, 2018: Global, regional and national prevalence estimates for intimate partner violence against women and global and regional prevalence estimates for non-partner sexual violence against women. Geneva: World Health Organization. 4 
World Bank (2020). Women, Business and the Law 2020. The World Bank. 4

Yilmaz, O. (2018). Female autonomy, social norms and intimate partner violence against women in turkey. The Journal of Development Studies 54(8), 1321-1337. 6 


\section{Appendix}

Figure A.1: Femicides over the years 2015-2019

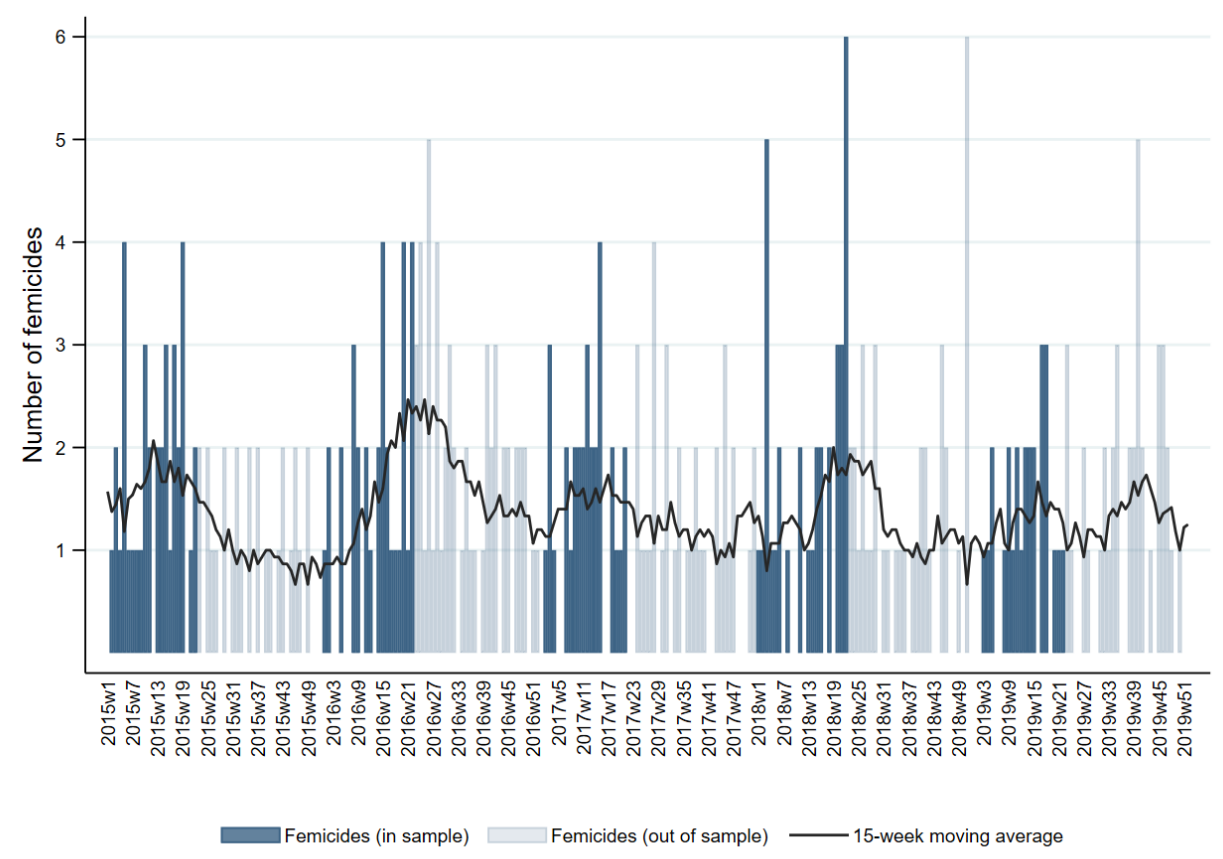

Note: Number of femicides by week (w). Dark blue bars correspond to femicides used in the empirical analysis, light blue bars represent femicides that are used for the falsification exercise. The black line indicates the 15-week moving average. 
Figure A.2: Distribution of femicides across provinces and time

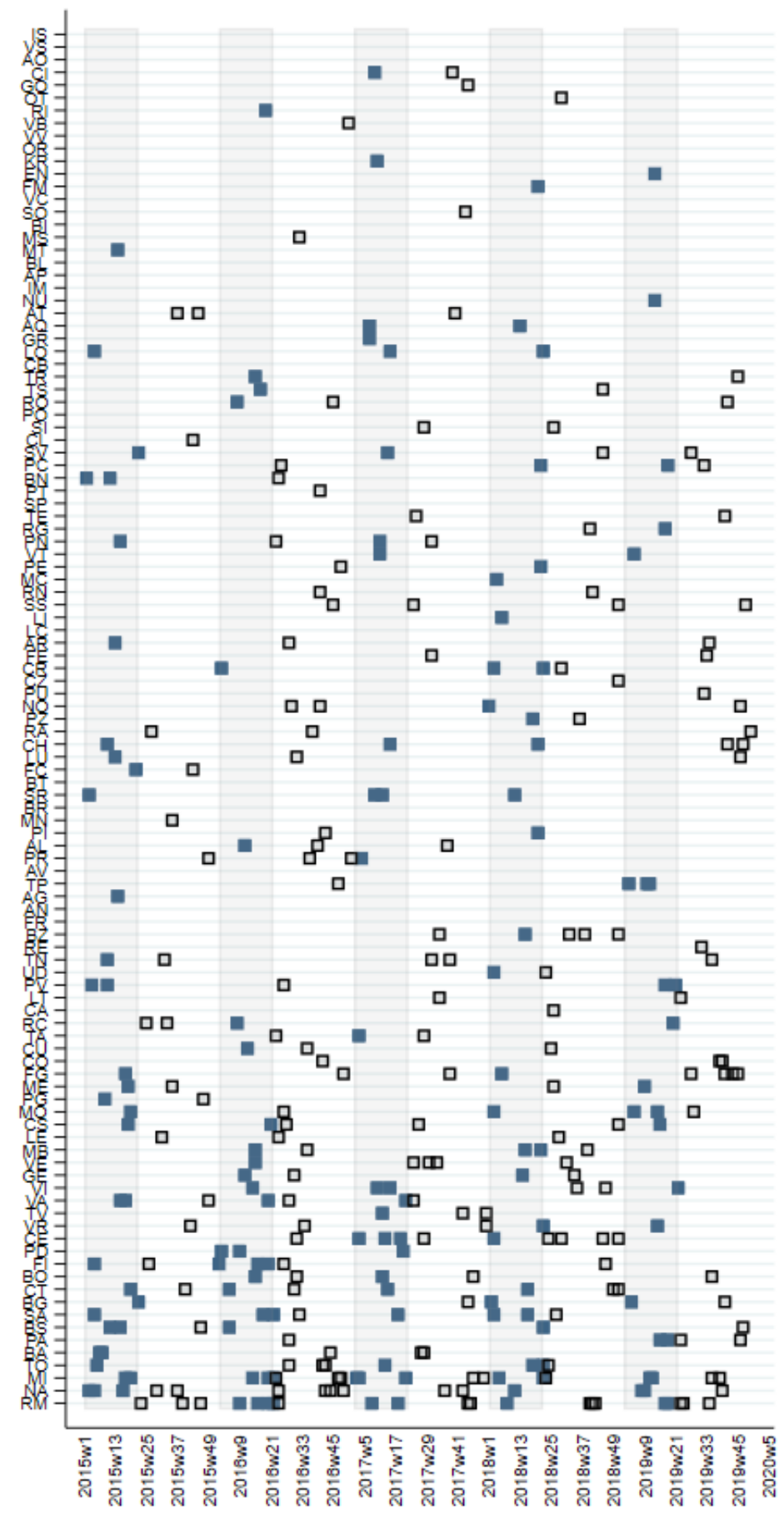

Eemicides (in sample) DFemicides (out of sample)

Note: Spatial-temporal distribution of the treatment. Each square represents a femicide in a given province in a given week (w). Events included in our sample are represented by blue squares, those included in the falsification exercise by white squares. The provinces are ordered by population size. 
Figure A.3: Matched controls and estimated average effect

Distribution of Matched Set Sizes

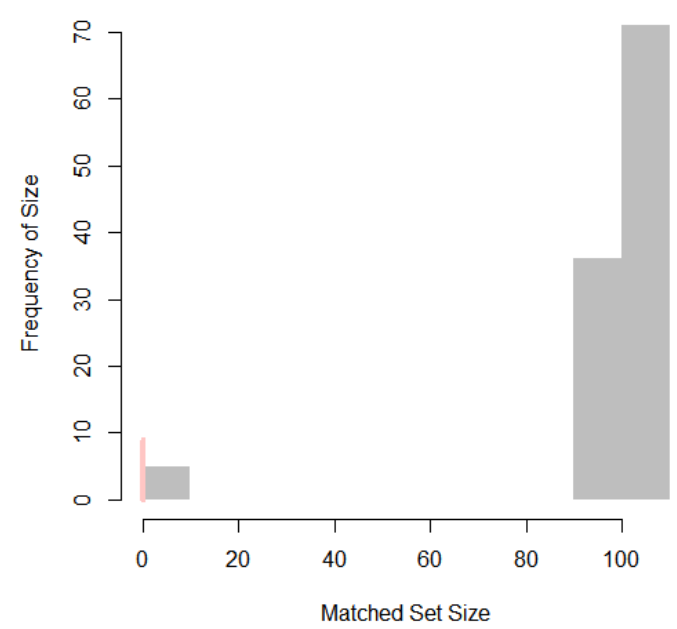

Estimated Effects of Treatment Over Time

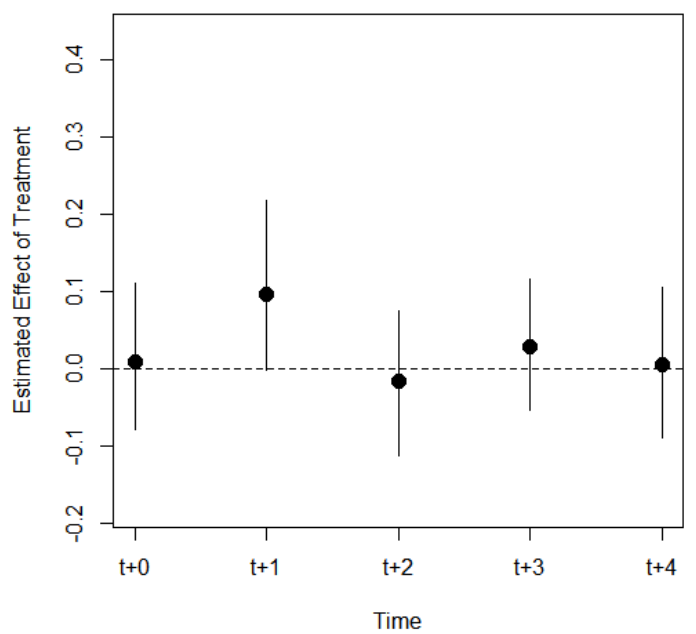

Note: Procedure suggested by Imai et al. (2021) and implemented via the PanelMatch R package. The left plot shows the number of matched control units that share the same treatment history as a treated observation. The red thin bar at zero represents the number of treated observations that have no matched control units. The right plot displays coefficients and corresponding $95 \%$ confidence intervals estimated based on a matching method that adjusts for the treatment and covariate histories during the four weeks period prior to the treatment.

Figure A.4: Helpline calls and femicides, adjacent provinces

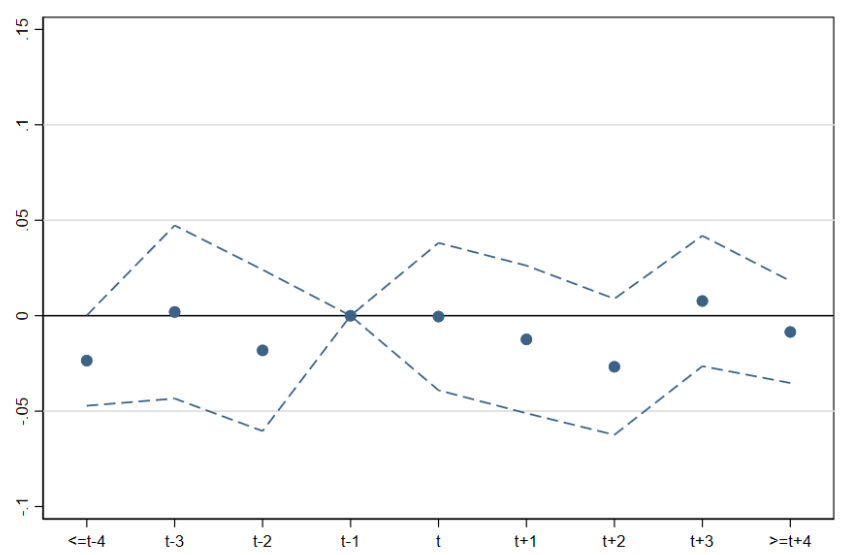

Note: OLS estimates of lags and leads and corresponding 95\% confidence intervals as from Equation 8. The baseline time period is $t-1$ (one week prior to the the occurrence of a femicide in a given province). The dependent variable is the number of calls to the 1522 helpline per 100,000 population. Estimates include province and week-year fixed effects. Standard errors are clustered at province level. 
Figure A.5: Helpline calls and femicides, placebo

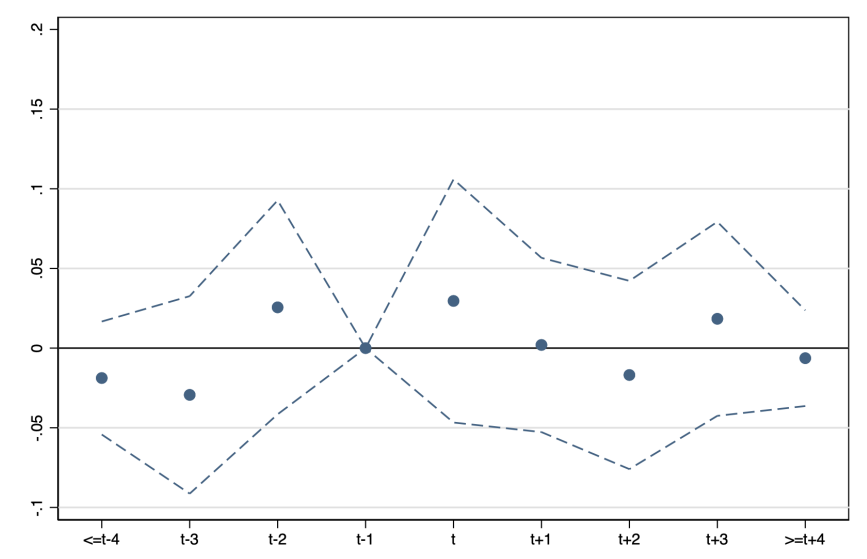

Note: OLS estimates of lags and leads and corresponding 95\% confidence intervals as from Equation 8. The baseline time period is $t-1$ (one week prior to the the occurrence of a femicide in a given province). The falsified treatment considers future femicides in the same province. The dependent variable is the number of calls to the 1522 helpline per 100,000 population. Estimates include province and week-year fixed effects. Standard errors are clustered at province level.

Table A.1: Helpline calls and female homicides

\begin{tabular}{lcc}
\hline Treatment & $(1)$ & $(2)$ \\
t-4 or earlier & Femicides & $\begin{array}{c}\text { Other } \\
\text { homicides }\end{array}$ \\
t-3 & 0.006 & -0.002 \\
& $(0.017)$ & $(0.027)$ \\
t-2 & 0.033 & -0.026 \\
& $(0.033)$ & $(0.058)$ \\
$\mathbf{t}$ & 0.030 & -0.024 \\
& $(0.030)$ & $(0.049)$ \\
$\mathbf{t}+\mathbf{1}$ & -0.018 & 0.035 \\
& $(0.032)$ & $(0.061)$ \\
$\mathbf{t}+\mathbf{2}$ & $0.092 * *$ & -0.047 \\
$\mathbf{t}+\mathbf{3}$ & $(0.044)$ & $(0.057)$ \\
$\mathbf{t}+\mathbf{4}$ or later & -0.043 & 0.017 \\
& $(0.030)$ & $(0.049)$ \\
\hline Observations & -0.001 & 0.028 \\
R-squared & $(0.025)$ & $(0.054)$ \\
\hline
\end{tabular}

Note: The baseline period is $t-1$ (one week prior to the event of interest). The dependent variable is the number of calls to the 1522 helpline per 100,000 population. Estimates include province and week-year fixed effects. Standard errors are clustered at province level. ${ }^{* * *} \mathrm{p}<0.01,{ }^{* *} \mathrm{p}<0.05,{ }^{*} \mathrm{p}<0.1$. 
Table A.2: Helpline calls and female homicides, robustness tests

\begin{tabular}{|c|c|c|c|c|c|c|c|}
\hline & (1) & $(2)$ & $(3)$ & $(4)$ & $(5)$ & (6) & $(7)$ \\
\hline t- 4 or earlier & $\begin{array}{c}0.008 \\
(0.016)\end{array}$ & $\begin{array}{c}0.013 \\
(0.016)\end{array}$ & $\begin{array}{c}0.013 \\
(0.016)\end{array}$ & $\begin{array}{l}-0.016 \\
(0.017)\end{array}$ & $\begin{array}{c}0.024 \\
(0.031)\end{array}$ & $\begin{array}{c}0.025 \\
(0.028)\end{array}$ & $\begin{array}{c}0.014 \\
(0.035)\end{array}$ \\
\hline $\mathrm{t}-3$ & $\begin{array}{c}0.034 \\
(0.033)\end{array}$ & $\begin{array}{c}0.038 \\
(0.033)\end{array}$ & $\begin{array}{c}0.038 \\
(0.033)\end{array}$ & $\begin{array}{c}0.017 \\
(0.036)\end{array}$ & $\begin{array}{c}0.056 \\
(0.054)\end{array}$ & $\begin{array}{c}0.059 \\
(0.052)\end{array}$ & $\begin{array}{c}0.063 \\
(0.065)\end{array}$ \\
\hline $\mathrm{t}-2$ & $\begin{array}{c}0.030 \\
(0.030)\end{array}$ & $\begin{array}{c}0.033 \\
(0.031)\end{array}$ & $\begin{array}{c}0.033 \\
(0.031)\end{array}$ & $\begin{array}{c}0.017 \\
(0.037)\end{array}$ & $\begin{array}{c}0.021 \\
(0.052)\end{array}$ & $\begin{array}{c}0.024 \\
(0.051)\end{array}$ & $\begin{array}{c}0.063 \\
(0.058)\end{array}$ \\
\hline $\mathbf{t}$ & $\begin{array}{c}-0.017 \\
(0.031)\end{array}$ & $\begin{array}{c}-0.013 \\
(0.031)\end{array}$ & $\begin{array}{c}-0.013 \\
(0.031)\end{array}$ & $\begin{array}{l}-0.034 \\
(0.035)\end{array}$ & $\begin{array}{l}-0.026 \\
(0.057)\end{array}$ & $\begin{array}{c}-0.021 \\
(0.056)\end{array}$ & $\begin{array}{c}-0.033 \\
(0.071)\end{array}$ \\
\hline$t+1$ & $\begin{array}{c}0.094^{* *} \\
(0.044)\end{array}$ & $\begin{array}{c}0.097^{* *} \\
(0.045)\end{array}$ & $\begin{array}{c}0.097^{* *} \\
(0.045)\end{array}$ & $\begin{array}{l}0.092^{*} \\
(0.053)\end{array}$ & $\begin{array}{l}0.137^{*} \\
(0.071)\end{array}$ & $\begin{array}{c}0.142^{* *} \\
(0.070)\end{array}$ & $\begin{array}{c}0.179 * * \\
(0.077)\end{array}$ \\
\hline $\mathrm{t}+\mathbf{2}$ & $\begin{array}{l}-0.042 \\
(0.031)\end{array}$ & $\begin{array}{l}-0.040 \\
(0.031)\end{array}$ & $\begin{array}{c}-0.040 \\
(0.031)\end{array}$ & $\begin{array}{l}-0.037 \\
(0.034)\end{array}$ & $\begin{array}{c}-0.084^{*} \\
(0.043)\end{array}$ & $\begin{array}{c}-0.081^{*} \\
(0.042)\end{array}$ & $\begin{array}{l}-0.097 \\
(0.068)\end{array}$ \\
\hline $\mathrm{t}+\mathbf{3}$ & $\begin{array}{l}-0.001 \\
(0.025)\end{array}$ & $\begin{array}{c}0.001 \\
(0.025)\end{array}$ & $\begin{array}{c}0.001 \\
(0.025)\end{array}$ & $\begin{array}{l}-0.050 \\
(0.034)\end{array}$ & $\begin{array}{l}-0.004 \\
(0.040)\end{array}$ & $\begin{array}{c}0.002 \\
(0.039)\end{array}$ & $\begin{array}{l}-0.001 \\
(0.051)\end{array}$ \\
\hline$t+4$ or later & $\begin{array}{c}-0.012 \\
(0.020)\end{array}$ & $\begin{array}{l}-0.009 \\
(0.020)\end{array}$ & $\begin{array}{l}-0.009 \\
(0.020)\end{array}$ & $\begin{array}{l}-0.026 \\
(0.025)\end{array}$ & $\begin{array}{c}0.000 \\
(0.027)\end{array}$ & $\begin{array}{c}0.007 \\
(0.024)\end{array}$ & $\begin{array}{l}-0.017 \\
(0.045)\end{array}$ \\
\hline Observations & 12,426 & 12,426 & 12,426 & 12,312 & 10,726 & 12,426 & 12,099 \\
\hline R-squared & 0.172 & 0.188 & 0.188 & 0.367 & 0.154 & 0.168 & \\
\hline Violence linear trends & $\checkmark$ & $\checkmark$ & $\checkmark$ & & & & \\
\hline Poverty linear trends & & $\checkmark$ & $\checkmark$ & & & & \\
\hline Education linear trends & & & $\checkmark$ & & & & \\
\hline Province-Year FE & & & & $\checkmark$ & & & \\
\hline Week-Year-Region FE & & & & $\checkmark$ & & & \\
\hline First event only & & & & & $\checkmark$ & $\checkmark$ & \\
\hline Estimator & OLS & OLS & OLS & OLS & OLS & OLS & PPML \\
\hline
\end{tabular}

Note: The baseline period is $t-1$ (one week prior to the event of interest). The dependent variable is the number of calls to the 1522 helpline per 100,000 population. Estimates include province and week-year fixed effects. Columns 1 to 4: province-specific linear trends based on the total number of female homicides (violence), the incidence of households in potential economic distress (poverty) and the incidence of illiterates (education). "First event only" means that a province is considered as treated once the first femicide occurs and that the observation from the second event onwards is dropped (column 5) or that the initial balanced sample is retained (column 6). The model is estimated using the Poisson's pseudo log-likelihood model (PPML, column 7). Standard errors are clustered at province level. *** $\mathrm{p}<0.01,{ }^{* *} \mathrm{p}<0.05,{ }^{*} \mathrm{p}<0.1$. 
Table A.3: Helpline calls and female homicides, by type of femicide

\begin{tabular}{|c|c|c|c|c|c|}
\hline Treatment & $\begin{array}{c}\text { (1) } \\
\text { Firearm }\end{array}$ & $\begin{array}{c}(2) \\
\text { Fight }\end{array}$ & Weapon & $\begin{array}{c}(4) \\
\text { Other }\end{array}$ & $\begin{array}{c}(5) \\
\text { Most } \\
\text { Googled }\end{array}$ \\
\hline \multicolumn{6}{|c|}{ Baseline: The effect of the news of a femicide } \\
\hline t- 4 or earlier & $\begin{array}{c}-0.002 \\
(0.018)\end{array}$ & $\begin{array}{c}0.007 \\
(0.018)\end{array}$ & $\begin{array}{c}0.010 \\
(0.019)\end{array}$ & $\begin{array}{c}0.006 \\
(0.017)\end{array}$ & $\begin{array}{c}0.018 \\
(0.018)\end{array}$ \\
\hline $\mathrm{t}-3$ & $\begin{array}{c}0.049 \\
(0.039)\end{array}$ & $\begin{array}{c}0.024 \\
(0.036)\end{array}$ & $\begin{array}{c}0.041 \\
(0.037)\end{array}$ & $\begin{array}{c}0.028 \\
(0.033)\end{array}$ & $\begin{array}{c}0.005 \\
(0.032)\end{array}$ \\
\hline $\mathrm{t}-2$ & $\begin{array}{c}0.020 \\
(0.034)\end{array}$ & $\begin{array}{c}0.025 \\
(0.032)\end{array}$ & $\begin{array}{c}0.055 \\
(0.039)\end{array}$ & $\begin{array}{c}0.030 \\
(0.031)\end{array}$ & $\begin{array}{l}-0.001 \\
(0.030)\end{array}$ \\
\hline $\mathbf{t}$ & $\begin{array}{l}-0.006 \\
(0.037)\end{array}$ & $\begin{array}{l}-0.007 \\
(0.032)\end{array}$ & $\begin{array}{l}-0.023 \\
(0.040)\end{array}$ & $\begin{array}{l}-0.019 \\
(0.033)\end{array}$ & $\begin{array}{l}-0.024 \\
(0.032)\end{array}$ \\
\hline$t+1$ & $\begin{array}{c}0.101^{* *} \\
(0.050)\end{array}$ & $\begin{array}{l}0.073^{*} \\
(0.042)\end{array}$ & $\begin{array}{l}0.108^{*} \\
(0.058)\end{array}$ & $\begin{array}{c}0.087^{*} \\
(0.046)\end{array}$ & $\begin{array}{l}0.065^{*} \\
(0.038)\end{array}$ \\
\hline$t+2$ & $\begin{array}{l}-0.044 \\
(0.034)\end{array}$ & $\begin{array}{l}-0.026 \\
(0.032)\end{array}$ & $\begin{array}{l}-0.036 \\
(0.037)\end{array}$ & $\begin{array}{l}-0.041 \\
(0.031)\end{array}$ & $\begin{array}{l}-0.044 \\
(0.035)\end{array}$ \\
\hline $\mathrm{t}+3$ & $\begin{array}{l}-0.007 \\
(0.027)\end{array}$ & $\begin{array}{c}0.003 \\
(0.026)\end{array}$ & $\begin{array}{c}0.023 \\
(0.031)\end{array}$ & $\begin{array}{c}0.003 \\
(0.026)\end{array}$ & $\begin{array}{l}-0.014 \\
(0.028)\end{array}$ \\
\hline$t+4$ or later & $\begin{array}{l}-0.007 \\
(0.022)\end{array}$ & $\begin{array}{l}-0.006 \\
(0.020)\end{array}$ & $\begin{array}{l}-0.017 \\
(0.025)\end{array}$ & $\begin{array}{l}-0.010 \\
(0.020)\end{array}$ & $\begin{array}{c}0.003 \\
(0.021)\end{array}$ \\
\hline \multicolumn{6}{|c|}{ Differential effect of the selected treatment } \\
\hline t- 4 or earlier & $\begin{array}{c}0.038 \\
(0.038)\end{array}$ & $\begin{array}{l}-0.007 \\
(0.031)\end{array}$ & $\begin{array}{l}-0.012 \\
(0.023)\end{array}$ & $\begin{array}{c}0.013 \\
(0.037)\end{array}$ & $\begin{array}{l}-0.046 \\
(0.029)\end{array}$ \\
\hline $\mathrm{t}-3$ & $\begin{array}{c}-0.071 \\
(0.058)\end{array}$ & $\begin{array}{c}0.044 \\
(0.081)\end{array}$ & $\begin{array}{l}-0.017 \\
(0.055)\end{array}$ & $\begin{array}{c}0.083 \\
(0.064)\end{array}$ & $\begin{array}{l}-0.048 \\
(0.067)\end{array}$ \\
\hline $\mathrm{t}-2$ & $\begin{array}{c}0.044 \\
(0.062)\end{array}$ & $\begin{array}{c}0.020 \\
(0.091)\end{array}$ & $\begin{array}{l}-0.059 \\
(0.051)\end{array}$ & $\begin{array}{l}-0.016 \\
(0.087)\end{array}$ & $\begin{array}{c}0.027 \\
(0.077)\end{array}$ \\
\hline $\mathbf{t}$ & $\begin{array}{l}-0.052 \\
(0.055)\end{array}$ & $\begin{array}{l}-0.048 \\
(0.078)\end{array}$ & $\begin{array}{c}0.015 \\
(0.045)\end{array}$ & $\begin{array}{c}0.010 \\
(0.058)\end{array}$ & $\begin{array}{c}0.007 \\
(0.077)\end{array}$ \\
\hline $\mathrm{t}+\mathbf{1}$ & $\begin{array}{c}-0.033 \\
(0.091)\end{array}$ & $\begin{array}{c}0.084 \\
(0.101)\end{array}$ & $\begin{array}{l}-0.034 \\
(0.059)\end{array}$ & $\begin{array}{c}0.076 \\
(0.083)\end{array}$ & $\begin{array}{c}0.123 \\
(0.107)\end{array}$ \\
\hline $\mathrm{t}+\mathbf{2}$ & $\begin{array}{c}0.002 \\
(0.058)\end{array}$ & $\begin{array}{l}-0.089 \\
(0.058)\end{array}$ & $\begin{array}{l}-0.016 \\
(0.047)\end{array}$ & $\begin{array}{l}-0.078 \\
(0.095)\end{array}$ & $\begin{array}{l}-0.078 \\
(0.056)\end{array}$ \\
\hline$t+3$ & $\begin{array}{c}0.021 \\
(0.060)\end{array}$ & $\begin{array}{l}-0.021 \\
(0.057)\end{array}$ & $\begin{array}{l}-0.053 \\
(0.039)\end{array}$ & $\begin{array}{l}-0.076 \\
(0.064)\end{array}$ & $\begin{array}{l}-0.025 \\
(0.055)\end{array}$ \\
\hline $\mathrm{t}+4$ or later & $\begin{array}{l}-0.020 \\
(0.031)\end{array}$ & $\begin{array}{l}-0.029 \\
(0.045)\end{array}$ & $\begin{array}{c}0.017 \\
(0.024)\end{array}$ & $\begin{array}{l}-0.007 \\
(0.055)\end{array}$ & $\begin{array}{l}-0.053 \\
(0.037)\end{array}$ \\
\hline Observations & 12,426 & 12,426 & 12,426 & 12,426 & 12,426 \\
\hline R-squared & 0.168 & 0.168 & 0.168 & 0.168 & 0.169 \\
\hline
\end{tabular}

Note: The baseline period is $t-1$ (one week prior to the event of interest). The dependent variable is the number of calls to the 1522 helpline per 100,000 population. Estimates include province and weekyear fixed effects. The weapon categories are defined as follows: firearm, fight (including any type of beating, pushing or strangling), knife or similar cutting objects, and other means (e.g., poison). "Most Googled" are femicides where the average Google queries containing the name of the victim in the four weeks following the murder are above the 75th percentile of the overall distribution. Standard errors are clustered at province level. ${ }^{* * *} \mathrm{p}<0.01,{ }^{* *} \mathrm{p}<0.05,{ }^{*} \mathrm{p}<0.1$. 


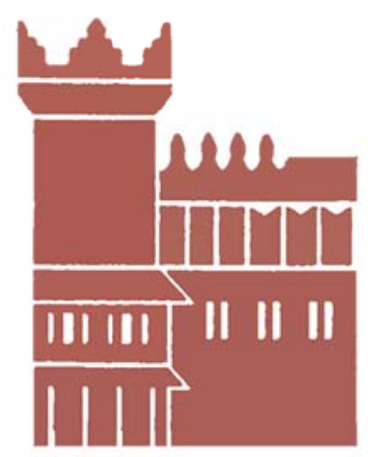

Alma Mater Studiorum - Università di Bologna DEPARTMENT OF ECONOMICS

Strada Maggiore 45

40125 Bologna - Italy

Tel. +39051 2092604

Fax +390512092664

http://www.dse.unibo.it 